INDONESIAN HEALTH ISSUE

\title{
Manfaat Kompres Dingin Pada Nyeri Perineum Kala IV
}

\author{
Durrotun Munafiah, Hermeksi Rahayu, Saadah Mujahidah, Mariza Mustika Dewi, Dian \\ Nuringtyas Rahayu
}

Universitas Karya Husada Semarang

Email korespondensi: durrotunmunafiah313@gmail.com

No HP: 085866518283

\section{ARTICLE INFO}

Kata Kunci:

Kompres dingin;

Nyeri perineum

\section{Keywords:}

Cold compress;

Perineal pain

\begin{abstract}
ABSTRAK
Latar Belakang: Rasa sakit yang dialami ibu saat persalinan kala IV disebabkan karena laserasi pada perinium. Laserasi tersebut terjadi karena adanya tindakan medis atas indikasi tertentu yaitu episiotomi atau terjadi ruptur perinium secara alami yang diakibatkan oleh desakan kepala bayi yang terlalu cepat. Laserasi perineum dapat menyebabkan nyeri dan ketidaknyamanan selama beberapa minggu. Tujuan: Menganalisa pengaruh kompres dingin perinium terhadap intensitas nyeri pada persalinan kala IV di ruang bersalin RSUD dr Gunawan Mangunkusumo Ambarawa) Metode: Penelitian ini merupakan quasi experiment. Desain penelitian post test with control group design. Sampel dalam penelitian ini adalah ibu bersalin pervaginam kala IV sejumlah 20 responden yang dibagi menajdi kelompok perlakuan dan kontrol dengan teknik pengambilan sampel non probability sampling. Penelitian ini menggunakan uji statistic Mann Whitney. Hasil: Intensitas nyeri Kala IV pada kelompok kontrol sesudah tindakan kompres dingin (air dingin) perinium rata-rata 5,80. Intensitas nyeri kala IV pada kelompok intervensi sesudah tindakan kompres dingin (es) perinium rata-rata 4,70 dengan nilai signifikansi $p<\alpha(0,05)$. Kesimpulan: Ada pengaruh kompres dingin perinium terhadap intensitas nyeri pada persalinan kala IV. Tenaga kesehatan terutama bidan sebaiknya dapat melakukan intervensi nonfarmakologi dengan memberikan kompres dingin perinium dan pijat perinium dalam upaya mengatasi masalah nyeri yang terdapat pada ibu bersalin kala IV.
\end{abstract}

ABSTRACT
Background: Pain experienced by the mother during the fourth stage of
labor is caused by laceration of the perineum. The laceration occurs
because of medical action for certain indications, namely an episiotomy
or natural perineal rupture caused by the pressure of the baby's head too
fast. Perineal lacerations can cause pain and discomfort for several
weeks. Purpose: To analyze the effect of perineal cold compresses on
pain intensity in the fourth stage of labor in the delivery room of RSUD Dr.
Gunawan Mangunkusumo Ambarawa. Methods: This study is a quasi-
experimental study. Post test research design with control group design.
The sample in this study were women who gave birth vaginally during the
fourth stage of the study with a total of 20 respondents who were divided
into treatment and control groups using non-probability sampling. This
study uses the Mann Whitney statistical test. Results: The fourth stage of
pain intensity in the control group after cold compresses (cold water) on
the perineum was on average 5.80 . The fourth stage of pain intensity in
the intervention group after the perineal cold compress (ice) was an


average of 4.70 with a significance value of $p<\alpha(0.05)$. Conclusion: There is an effect of perineal cold compresses on the intensity of pain in the fourth stage of labor. Health workers especially midwives, should be able to carry out non-pharmacological interventions by providing perineal cold compresses and perineal massage in an effort to overcome the pain problems found in women giving birth in the fourth stage.

(c) (i) (2) 2021 by the authors. Submitted for possible open access publication under the terms and conditions of the Creative Commons Attribution (CC BY SA) license (https://creativecommons.org/licenses/by-sa/4.0/). 


\section{PENDAHULUAN}

Persalinan dan kelahiran merupakan kejadian fisiologi yang normal dalam kehidupan. Peranan petugas kesehatan tidak kalah penting dalam memberikan dukungan dan bantuan pada ibu agar seluruh rangkaian proses persalinan berlangsung dengan aman dan baik bagi ibu dan bayi. Jika semua tenaga penolong persalinan dilatih agar mampu mencegah atau deteksi dini komplikasi yang mungkin terjadi, menerapkan asuhan persalinan secara tepat guna dan waktu, baik sebelum atau saat terjadi masalah dan segera melakukan rujukan maka para ibu dan bayi baru lahir akan terhindar dari ancaman kesakitan dan kematian. Bagaimanapun deteksi dini dan pencegahan komplikasi merupakan cara efektif dalam menurunkan angka kematian dan kesakitan ibu serta bayi baru lahir (Utami \& Enny, 2019).

Proses persalinan pasti disertai rasa sakit yang disebabkan aktivitas besar dalam tubuh. Baik itu persalinan perabdominal maupun pervaginam, perbedaaanya adalah pada persalinan perabdominal, rasa sakit terjadi setelah proses persalinan selesai yaitu nyeri pada jahitan di perut. Sedangkan pada persalinan pervaginam nyeri persalinan terjadi sebelum janin keluar yaitu saat kala I pembukaan serviks, kala II saat pengeluaran bayi, kala III saat pengeluaran plasenta dan kala IV saat penjahitan perinium apabila terjadi ruptur perinium (Choirunissa, 2019; Hamidah, 2019; Putri, 2016).

Beberapa teknik dapat dilakukan untuk mengurangi nyeri luka perinium salah satunya adalah dengan kompres dingin perinium. Beberapa cara nonfarmakologi telah dilakukan dan diteliti efektif mengurangi nyeri pada perinium. Penelitian terdahulu yang dilakukan oleh Eva Sliviana Rahmawati tahun 2013 diperoleh hasil terapi kompres dingin perinium efektif mengurangi nyeri pada perinium. Dimana diperoleh hasil setelah dilakukan kompres dingin perinium sebagian besar responden mengalami nyeri ringan 15 responden $(75 \%)$, nyeri sedang 4 responden $(20 \%)$ serta nyeri berat 1 responden (5\%) (Silviana, 2013).

Pencegahan rasa sakit dalam persalinan telah menjadi tujuan utama asuhan persalinan pada tenaga kesehatan khususnya bidan dalam memberikan pelayanan asuhan kebidanan dalam asuhan sayang ibu agar dapat bersalin dengan nyaman, sehat dan tanpa rasa nyeri yang berlebihan. Bidan memiliki peran dan tanggung jawab sebagai tenaga kesehatan untuk memberikan asuhan kebidanan secara biopsiko-sosial dan spiritual. Salah satu peran bidan dalam persalinan adalah dengan metode nonfarmakologis yang dapatdigunakan oleh bidan dalam mengurangi tingkat nyeri ibu pada saat persalinan kala IV yaitu metode kompres dingin perinium dengan harapan akan mudah diterima oleh ibu bersalin (Putri, 2016; Rahmawati, 2013; Silviana, 2013).

Berdasarkan hasil studi pendahuluan yang dilakukan peneliti di ruang bersalin RSUD dr Gunawan Mangunkusumo Ambarawa pada bulan Januari sampai Desember tahun 2020 didapatkan hasil yaitu 399 jumlah persalinan pervaginam dengan rata-rata tiap bulan yakni 33 orang ibu bersalin normal, 725 ibu bersalin Sectio Cesarea dan vacum 1 orang ibu. Dari sebagian besar ibu bersalin pervaginam tersebut, hampir seluruhnya mengalami robekan perinium baik pada primipara maupun multipara. Hasil wawancara kepada bidan, dari 33 ibu bersalin baik primi maupun multipara sebanyak 28 ibu mengatakan nyeri perinium baik pada saat tindakan penjahitan perinium dan sesudah penjahitan perinium. Sebagian besar ibu primipara mengalami takut saat buang air kecil dan saat duduk. Upaya yang sudah dilakukan di ruang bersalin RSUD dr Gunawan Mangunkusumo Ambarawa selama ini dalam menangani nyeri saat penjahitan laserasi perinium adalah pemberian edukasi oleh bidan kepada ibu bersalin dan keluarganya dan pemberian anestetik 
lokal dan analgesik peroral. Upaya edukasi dan pemberian obat farmakologi tersebut ternyata masih belum dapat mengatasi rasa nyeri tersebut.

\section{METODE PENELITIAN}

Peneltian ini merupakan penelitian quasy experiment dengan posttest with control group design. Penelitian dilakukan di Ruang Bersalin RSUD dr. Gunawan Mangunkusumo Ambarawa pada bulan Juli 2021. Populasi penelitian ini adalah semua ibu bersalin yang memiliki HPL pada bulan Juni - Agustus 2021 sebanyak 35 orang. Sampel penelitian ini adalah 20 ibu bersalin yang dibagi menjadi kelompok perlakuan dan kontrol. Kelompok perlakuan diberikan kompres es, sedangkan kelompok kontrol diberikan kompres air dingin. Penelitian ini menggunakan teknik non probability sampling jenis purposive sampling. Pengumpulan data dalam penelitian ini menggunakan data primer dan data sekunder. Analisis data yang digunakan pada penelitian ini adalah uji Mann Whitney dengan nilai $p$-value $<0,05$.

\section{HASIL PENELITIAN}

Penelitian ini dilakukan di Ruang bersalin RSUD dr. Gunawan Mangunkusumo Ambarawa pada bulan Juli 2021 dengan 20 ibu bersalin dengan 10 ibu bersalin diberikan perlakuan kompres es, dan 10 ibu bersalin diberikan kompres dingin.

Tabel 1. Distribusi Frekuensi Responden berdasarkan Intensitas Nyeri Kala IV sesudah Tindakan di Ruang Bersalin RSUD dr. Gunawan Mangunkusumo Ambarawa tahun 2021

\begin{tabular}{lcccccc}
\hline & Variabel & n & Mean & SD & Min & Max \\
\hline Intensitas Nyeri Kala IV Pada & 10 & 5,80 & 0,789 & 5 & 7 \\
$\begin{array}{l}\text { Kelompok Kontrol Sesudah } \\
\text { Tindakan Kompres Dingin (Air }\end{array}$ & & & & & \\
Dingin) & & & & & \\
\hline $\begin{array}{l}\text { Intensitas Nyeri Kala IV Pada } \\
\text { Kelompok Intervensi Sesudah }\end{array}$ & 10 & 4,70 & 0,823 & 3 & 6 \\
Tindakan Kompres Dingin (Es) & & & & & \\
\hline Sumber : Data Primer, 2021
\end{tabular}

Tabel 1 diketahui bahwa intensitas nyeri kala IV pada kelompok kontrol sesudah tindakan kompres dingin (air dingin) rata-rata 5,80. Intensitas nyeri kala IV pada kelompok intervensi sesudah tindakan kompres dingin (es) rata-rata 4,70.

Tabel 2. Pengaruh Kompres Dingin Perineum terhadap Intensitas Nyeri pada Persalinan Kala IV di Ruang Bersalin RSUD dr. Gunawan Mangunkusumo Ambarawa tahun 2021

\begin{tabular}{lllllll}
\hline \multicolumn{2}{c}{ Variabel } & & n & Median & $\begin{array}{l}\text { Mean } \\
\text { Rank }\end{array}$ & P-Value \\
\hline $\begin{array}{lllllll}\text { Intensitas nyeri } \\
\text { kontrol (air dingin) }\end{array}$ & kelompok & 10 & 6 & 13,70 & \multirow{2}{*}{0,009} \\
\cline { 1 - 5 } $\begin{array}{l}\text { Intensitas nyeri } \\
\text { intervensi (es) }\end{array}$ & kelompok & 10 & 5 & 7,30 & \\
\hline
\end{tabular}

Sumber : Data Primer, 2021

Tabel 2 menggunakan uji Mann Whitney dengan nilai signifikansi $p$-value $<0,05$ menyatakan bahwa pengaruh kompres dingin (es) perinium lebih efektif jika dibandingkan dengan kompres dingin (air dingin ) terhadap intensitas nyeri pada persalinan kala IV di Ruang Bersalin RSUD dr Gunawan Mangunkusumo Ambarawa. 


\section{PEMBAHASAN}

\section{Intensitas Nyeri Kala IV pada Kelompok Kontrol sesudah Tindakan Kompres Dingin (Air Dingin) Perinium Di Ruang Bersalin RSUD dr Gunawan Mangunkusumo Ambarawa}

Hasil penelitian menunjukkan intensitas nyeri kala IV sesudah tindakan kompres dingin (air dingin) perinium di ruang bersalin RSUD dr Gunawan Mangunkusumo Ambarawa menunjukkan sebagian besar menunjukkan rata-rata 5,80 dengan standar deviasi 0,789. Nyeri terendah 5 dan nyeri tertinggi 7 .

Kompres dingin merupakan modalitas terapi fisik yang menggunakan sifat fisik dingin untuk terapi berbagai kondisi, termasuk pada nyeri luka perineum. Kompres dingin bekerja dengan menstimulasi permukaan kulit untuk mengontrol nyeri. Terapi dingin yang diberikan akan mempengaruhi impuls yang dibawa oleh serabut taktil $A$ Beta untuk lebih mendominasi sehingga "gerbang" akan menutup dan impuls nyeri akan terhalangi. Nyeri yang dirasakan akan berkurang atau hilang untuk sementara waktu. Tujuan dilakukannya kompres dingin yaitu untuk mengurangi inflamasi yang terjadi pada tempat yang terserang nyeri sehingga sensasi nyeri pasien dapat berkurang (Putri, 2016; Rahmawati, 2013; Sari et al., 2018; Yuliatun, 2019).

Penelitian Ristu Wiyani, Jumratul Adawiah (2018) menunjukkan hasil lama penyembuhan luka pada ibu nifas yang menggunakan kompres dingin sebagian besar $(55,56 \%)$ responden mengalami penyembuhan luka $\leq 5$ hari dan hampir setengahya $(44,44 \%)$ responden mengalami penyembuhan luka $>5$ hari. Manfaat kompres dingin diantaranya adalah mengurangi aliran darah ke daerah luka sehingga dapat mengurangi resiko perdarahan dan oedema, kompres dingin menimbulkan efek analgetik dengan memperlambat kecepatan hantaran saraf sehingga impuls nyeri yang mencapai otak akan lebih sedikit (Wiyani, Ristu dan Adawiah, 2018).

Penelitian Elly Susilawati (2019), menunjukkan hasil nilai rata-rata intensitas nyeri luka perineum sebelum diberikan terapi kompres dingin adalah 4,80 dan setelah diberikan terapi terjadi penurunan intensitas nyeri dengan nilai rata-rata 1,33. Hasil tersebut menunjukkan bahwa terjadi penurunan nilai rata-rata intensitas nyeri luka perineum pada ibu post partum setelah diberikan kompres dingin (Susilawati \& Ilda, 2019).

\section{Intensitas Nyeri Kala IV pada Kelompok Intervensi sesudah Tindakan Kompres Dingin (Es) Perinium Di Ruang Bersalin RSUD dr Gunawan Mangunkusumo Ambarawa}

Hasil penelitian menunjukkan bahwa intensitas nyeri kala IV pada kelompok intervensi sesudah tindakan kompres dingin (es) rata-rata 4,70 dengan standar deviasi 0,823. Nyeri terendah 3 dan nyeri tertinggi 6 .

Kompres dingin (es) akan menyebabkan ibu postpartum merasa nyaman, karena efek analgetik dari kompres dingin yang menurunkan kecepatan hantaran syaraf sehingga impuls nyeri yang sampai ke otak lebih sedikit sehingga menurunkan sensasi nyeri yang dirasakan. Kompres es dapat meminimalkan terjadinya edema dengan mengurangi permeabilitas kapiler yang menurunkan rasa nyeri luka perineum. Hal ini didukung oleh teori yang menyatakan bahwa terapi 
kompres dingin mengurangi rasa nyeri, mencegah edema, mengontrol peredaran darah dengan meningkatkan vasokontriksi dan memenuhi kebutuhan rasa aman. (Rochmiyati, Shinta Nur dan Ummah, 2019)

Penelitian Elly Susilawati (2019), menunjukkan hasil nilai rata-rata intensitas nyeri luka perineum setelah diberikan terapi kompres dingin terjadi penurunan intensitas nyeri dengan nilai rata-rata 1,33. Hasil tersebut menunjukkan bahwa terjadi penurunan nilai rata-rata intensitas nyeri luka perineum pada ibu post partum setelah diberikan kompres dingin. Penggunaan kompres dingin terbukti dapat menghilangkan nyeri, Dampak fisiologisnya adalah vasokontriksi pada pembuluh darah, mengurangi rasa nyeri, dan menurunkan aktivitas ujung saraf pada otot. ${ }^{(17)}$ Penelitian Choirunisa menunjukkan hasil pada kelompok perlakuan kompres dingin nilai rata-rata intensitas nyeri luka perineum sebelum diberikan terapi adalah 4,80 dan setelah diberikan terapi kompres hangat terjadi penurunan intensitas nyeri dengan nilai rata-rata 1,38 . Kompres dingin adalah prosedur untuk menempatkan objek pada luar dingin tubuh. Psikologi dampak adalah vasokonstriksi pembuluh darah, mengurangi rasa sakit, dan mengurangi aktivitas ujung saraf pada otot. Setelah diberikan kompres dingin pada sebagian perineum ibu postpartum mengalami tingkat nyeri ringan (Choirunissa, 2019).

\section{Pengaruh Kompres Dingin Perinium Terhadap Intensitas Nyeri Pada Persalinan Kala IV di Ruang Bersalin RSUD dr Gunawan Mangunkusumo Ambarawa}

Penelitian menunjukkan ada pengaruh kompres dingin perinium terhadap intensitas nyeri pada persalinan kala IV di Ruang Bersalin RSUD dr Gunawan Mangunkusumo Ambarawa. Penelitian menunjukkan kompres es lebih efektif menurunkan nyeri persalinan kala IV dibandingkan kompres air dingin. Hal ini dikarenakan kompres es dapat menyebabkan transmisi nyeri tertutup sehingga cortex cerebri tidak dapat menerima sinyal karena nyeri sudah diblok dengan stimulasi dingin yang mencapai otak lebih dulu.

Secara teori kompres dingin dapat menghilangkan nyeri. Cara kerja dari kompres dingin adalah dengan pelepasan endorphin, sehingga memblok transmisi serabut saraf sensori A-beta yang lebih besar dan lebih cepat. Proses ini menurunkan transmisi nyeri melalui serabut $\mathrm{C}$ dan delta-A berdiameter kecil, sehingga gerbang sinap menutup transmisi impuls nyeri (Sari et al., 2018) (Potter, P.A \& Perry, 2016).

Endorphin merupakan substansi seperti morfin yang diproduksi oleh tubuh (termasuk zat kimiawi endogen) dan mempunyai konsentrasi kuat dalam sistem saraf. Endorphin ini berfungsi sebagai inhibitor terhadap transmisi nyeri dengan memblok transmisi impuls otak dan medulla spinalis. Kompres dingin digunakan untuk meredakan nyeri dengan memperlambat kecepatan konduksi saraf, menyebabkan mati rasa dan bekerja sebagai counterirritant. Pemberian tindakan aplikasi dingin dapat menurunkan nyeri dan meningkatkan penyembuhan. Aplikasi dingin

berkaitan dengan melambatnya kemampuan saraf- saraf nyeri dalam menyalurkan rangsangan nyeri. (Potter, P.A \& Perry, 2016)

Respon neurohormonal terhadap kompres es adalah pelepasan endorphin, penurunan transmisi saraf sensoris, penurunan aktivitas badan sel saraf, penurunan iritan yang merupakan limbah metabolisme sel. Pemberian kompres es juga merupakan salah satu cara untuk memberikan stimulasi pada kulit sehingga bersifat 
terapeutik. Stimulasi ini mengirimkan impuls dari perifer ke hipotalamus yang kemudian menjadi sensasi temperature tubuh secara normal (Rahmawati, 2013)(Potter, P.A \& Perry, 2016).

Penelitian terdahulu yang dilakukan oleh Eva Sliviana Rahmawati tahun 2013 diperoleh hasil terapi kompres dingin perinium efektif mengurangi nyeri pada perinium. Dimana diperoleh hasil setelah dilakukan kompres dingin perinium sebagian besar responden mengalami nyeri ringan 15 responden (75\%), nyeri sedang 4 responden (20\%) serta nyeri berat 1 responden (5\%). Analisis data menunjukkan ada pengaruh kompres dingin terhadap pengurangan nyeri luka perineum pada ibu nifas di BPS Siti Alfirdaus Kingking Kabupaten Tuba (Silviana, 2013).

Penelitian lain yang dilakukan oleh Ayang Dyaning pada tahun 2016 menunjukkan setelah post tes 1 jam menunjukkan nyeri sedang 6 responden $(60 \%)$, nyeri berat 1 responden (10\%). Setelah 24 jam post test menunjukkan nyeri ringan sejumlah 9 responden (90\%) dan nyeri sedang sebanyak 1 responden (10\%) (Putri, 2016).

\section{SIMPULAN DAN SARAN}

Intensitas nyeri Kala IV pada kelompok kontrol sesudah tindakan kompres dingin (air dingin) perinium rata-rata 5,80. Intensitas nyeri kala IV pada kelompok intervensi sesudah tindakan kompres dingin (es) perinium rata-rata 4,70. Ada pengaruh kompres dingin perinium terhadap intensitas nyeri pada persalinan kala IV di Ruang Bersalin RSUD dr Gunawan Mangunkusumo Ambarawa. Kompres es perinium lebih efektif dibanding kompres dingin basah perinium dalam mengurangi nyeri pada persalinan Kala IV. Institusi pendidikan diharapkan dapat memberikan kontribusi berupa literatur dan studi kepustakaan bagi perkembangan ilmu kebidanan terkait mengurangi nyeri perinium khususnya terapi non farmakologi pada ibu bersalin kala IV berupa kompres es pada perinium. Tenaga kesehatan sebaiknya dapat melakukan intervensi nonfarmakologi dengan memberikan kompres es perinium dalam upaya mengatasi masalah nyeri yang terdapat pada ibu bersalin kala IV. Peneliti selanjutnya sebaiknya dapat mengembangkan penelitian dengan melakukan terapi lain untuk mengurangi nyeri persalinan Kala IV misalnya dengan memberikan terapi genggam jari, terapi murotal, atau inovasi koaborasi terapi aromaterapi dan kompres es.

\section{DAFTAR PUSTAKA}

Choirunissa. (2019). Efektifitas kompres hangat dan dingin terhadap nyeri laserasi perineum pada ibu postpartum primipara di depok 2019. Universitas Nasional Jakarta Postal, 3(6), $37-44$.

Hamidah, S. (2019). PENGURANGAN NYERI PERSALINAN DENGAN KOMPRES HANGAT PADA IBU INPARTU DI RUMAH SAKIT MUHAMMADIYAH GRESIK. Jurnal Surya, 11(01), 8-14.

Potter, P.A \& Perry, A. . (2016). Fundamental Keperawatan, Konsep, Klinis dan Praktek. Penerbit Buku Kedokteran EGC.

Putri, D. A. (2016). Pengaruh Kompres Dingin Terhadap Tingkat Nyeri Perinium Pada Ibu Nifas di RSU PKU Muhammadiyah Bantul. Yogyakarta : Naskah Publikasi.

Rahmawati, E. S. (2013). Pengaruh kompres dingin terhadap pengurangan nyeri luka perineum pada ibu nifas di BPS Siti Alfirdaus Kingking Kabupaten Tuban. Jurnal Sain Med, 5(2), 43-46.

Rochmiyati, Shinta Nur dan Ummah, K. (2019). Pijat Perinium Selama Kehamilan. 
Surabaya: CV Jakad Publishing.

Sari, D. P., Rufaida, Z., \& Lestari, S. W. P. (2018). Nyeri persalinan. E-Book Penerbit STIKes Majapahit, 1-30.

Silviana, E. (2013). Pengaruh Kompres Dingin terhadap Pengurangan Nyeri Luka Perinium Pada Ibu NIfas di BPS Siti Alfirdaus Kingking Kabupaten Tuban. Jurnal Sain Med, Vol. 5.

Susilawati, E., \& Ilda, W. R. (2019). Efektifitas Kompres Hangat dan Kompres Dingin Terhadap Intensitas Nyeri Luka Perineum Pada Ibu Post Partum di BPM Siti Julaeha Pekanbaru. JOMIS (Journal Of Midwifery Science), 3(1), 7-14.

Utami, F., \& Enny, F. (2019). Buku Ajar Asuhan Persalinan \& Managemen Nyeri Persalinan. Universitas Aisyiyiah Yogyakarta, 284, 95-108.

Wiyani, Ristu dan Adawiah, J. (2018). Efektivitas Kompres Dingin Terhadap lama Penyembuhan Luka Rupture Perinium Pada Ibu Post Partum. Urnal Darul Azhar, Vol. 5, Hal. 64-71.

Yuliatun, L. (2019). Penanganan Nyeri Persalinan Dengan Metode Nonfarmakologis. Bayumedia Publishing. 